\title{
Characteristics of soil seed banks at different geomorphic positions within the longitudinal sand dunes of the Gurbantunggut Desert, China
}

\author{
JIA Fengqin ${ }^{1,2,3}$, Tashpolat TIYIP ${ }^{2}$, WU Nan ${ }^{1}$, TIAN Changyan ${ }^{1}$, ZHANG Yuanming ${ }^{1 *}$ \\ ${ }^{1}$ Key Laboratory of Biogeography and Bioresources in Arid Land, Xinjiang Institute of Ecology and Geography, Chinese \\ Academy of Sciences, Urumqi 830011, China; \\ ${ }^{2}$ Key Laboratory of Oasis Ecology/Resources and Environment Department, Xinjiang University, Urumqi 830046, China; \\ ${ }^{3}$ Tourism College, Urumqi Vocational University, Urumqi 830002, China
}

\begin{abstract}
Understanding the characteristics of soil seed banks in sand dunes is crucial to stabilize the dune systems and maintain the plant populations in deserts. In this study, we conducted a survey investigation in the field and a seed germination experiment in the laboratory to explore the characteristics of soil seed banks at various geomorphic positions of longitudinal sand dunes in the Gurbantunggut Desert, China. Totally, 17 plant species belonging to 17 genera and 9 families were identified in soil seed banks, and 35 plant species belonging to 34 genera and 17 families were identified in aboveground vegetation. Plant species richness in soil seed banks decreased with increasing soil depth. The highest species richness was presented in the upper slope of the windward slope and the lowest species richness was presented in the base of the windward slope. There was no significant difference in seed density of soil seed banks among the examined seven geomorphic positions. The highest seed density occurred in the lower slope of the leeward slope while the lowest occurred in the crest. Moreover, seed density decreased with increasing soil depth, being the highest in the upper soil layer $(0-2 \mathrm{~cm})$. For both soil seed banks and aboveground vegetation, there was no significant difference in Simpson's diversity index among the seven geomorphic positions; however, Shannon-Wiener diversity index and Pielou's evenness index showed significant differences among the seven geomorphic positions. Those results showed that although there was no significant difference in seed density of soil seed banks among the seven geomorphic positions, the geomorphic positions significantly affected the species richness, diversity and distribution of soil seed banks. Therefore, understanding the characteristics of soil seed banks at different geomorphic positions of sand dunes is essential to vegetation restoration or reestablishment. Furthermore, the Jaccard's similarity coefficients of plant species between soil seed banks and aboveground vegetation at the seven geomorphic positions were low, suggesting that vegetation restoration or reestablishment processes should be promoted through adding seeds to surface layers.
\end{abstract}

Keywords: soil seed banks; geomorphic position; seed density; species diversity; sand dunes; Gurbantunggut Desert

Citation: JIA Fengqin, Tashpolat TIYIP, WU Nan, TIAN Changyan, ZHANG Yuanming. 2017. Characteristics of soil seed banks at different geomorphic positions within the longitudinal sand dunes of the Gurbantunggut Desert, China. Journal of Arid Land, 9(3): 355-367. doi: 10.1007/s40333-017-0055-x

\section{Introduction}

Soil seed bank, referring to the viable seeds on or in the soil, can influence the ecosystems at

*Corresponding author: ZHANG Yuanming (E-mail: zhangym@ms.xjb.ac.cn)

Received 2016-08-08; revised 2016-11-23; accepted 2017-01-04

(C) Xinjiang Institute of Ecology and Geography, Chinese Academy of Sciences, Science Press and Springer-Verlag Berlin Heidelberg 2017 
genetic, species, population, and community scales (Hyatt and Casper, 2000). Thus, it plays an important role in ecosystem restoration (Bekker et al., 1998). Soil seed bank acts as not only the last natural species pool for ecosystem resilience in isolated and highly fragmented regions (Lindner, 2009), but also an important source for regenerating species-rich vegetation. It was early noted that more than $85 \%$ of the vegetation restoration or reestablishment relies on the soil seed banks (Lawton and Putz, 1988).

Soil seed bank changes greatly at regional scales and also at ecosystem scales (Wu et al., 2009). For example, in desert ecosystems, soil seed bank differs significantly between active sand dunes and fixed sand dunes (Ma and Liu, 2008). Even, soil seed bank may differ at dune scales, such as different slope aspects (Leicht-Young et al., 2009; Liu et al., 2011) and different geomorphic positions (e.g., base, windward slope, leeward slope, and crest). And unfortunately, no consensus has yet been reached regarding soil seed bank variations at dune scales. For example, Yan et al. (2009) reported that seed density of soil seed bank decreased from the base to the crest in active sand dunes while increased from the crest to the base in fixed sand dunes. However, Ma and Liu (2008) and Liu et al. (2011) reported that although soil seed bank differed at different geomorphic positions (e.g., base, windward slope, leeward slope, and crest) within the same sand dune, the variation could not be simply summarized as a monotonic (i.e., increasing or decreasing) trend. Vertical distribution of seeds was also noted to be crucial to understanding the soil seed banks in desert ecosystems (Huang and Gutterman, 1998). It was previously reported that with increasing soil depth, seed density of soil seed banks showed either a decreasing trend ( $\mathrm{Li}$ et al., 2007), or a U-shaped (bimodal) pattern (Decocq et al., 2004), or an increasing trend (Espinar et al., 2005), or an anomalous trend (Devictor et al., 2007). Again unfortunately, no consensus has been reached.

Gurbantunggut Desert is the largest fixed and semi-fixed sand dune-featured desert in arid and semi-arid regions of China (Wang et al., 2003; Qian et al., 2013). However, in recent years, commercial activities in the Gurbantunggut Desert, such as oil exploitation, tourism, nomadic activities and tillage, have massively destroyed the aboveground vegetation. Consequently, the sand dunes in the Gurbantunggut Desert have been massively activated. It is thus urgent to implement vegetation restoration or reestablishment strategies to mitigate these negative effects (Wang et al., 2009). Understanding the characteristics of soil seed banks in sand dunes is definitely needed to better utilize the soil seed banks in vegetation restoration or reestablishment in the Gurbantunggut Desert. Thus, we conducted a survey investigation at different geomorphic positions of sand dunes in the field and a seed germination experiment in the laboratory to further explore the characteristics of soil seed banks in sand dunes in the Gurbantunggut Desert. It is our hope that the findings could provide reference to vegetation restoration or reestablishment.

\section{Materials and methods}

\subsection{Study area}

The study area is located in the southern region of the Gurbantunggut Desert $\left(44^{\circ} 36^{\prime} \mathrm{N}, 88^{\circ} 14^{\prime} \mathrm{E}\right.$; $450 \mathrm{~m}$ a.s.l.; Fig. 1), Xinjiang, Northwest China. Its landscapes are mainly dominated by longitudinal sand dunes with the length of several kilometers and the height of 10-50 m. These longitudinal sand dunes have three major characteristics: (i) the base parts are usually flat and stabilized; (ii) the mid-lower parts are characterized by gentle slopes with the leeward slope being steeper than the windward slope; and (iii) the crests are domelike shaped and normally active zones (Wang et al., 2003). The average annual precipitation is about $70-150 \mathrm{~mm}$ and the annual pan evaporation is more than $2000 \mathrm{~mm}$. It should be noted that precipitation mainly occurs from April to July and snowfall generally lasts from preceding late November to succeeding early February (Song et al., 2011). The annual average temperature ranges from $6.68^{\circ} \mathrm{C}$ to $7.73^{\circ} \mathrm{C}$, and the coldest and hottest months are January and July, respectively.

Vegetation in the study area generally comprises shrubs, perennial herbs, annual herbs, and ephemeral plants (Zhang and Liu, 2012; Qian et al., 2013; Luo et al., 2016). The most abundant shrub species are Haloxylon persicum (Chenopodiaceae) distributed on the upper slopes and the 
crest of the sand dune, and H. ammodendron and Ephedra distachya (Ephedraceae) distributed in inter-dunes and on the lower slopes with well-developed biological soil crusts. The most abundant perennial herbs include Stipa glareosa (Gramineae) and Soranthus meyri (Umbelliferae); the most abundant annual herbs comprise Agriophyllum squarrosum (Chenopodiaceae) and Arnebia decumbens (Boraginaceae); and the most abundant ephemeral plants include Bassia dasyphylla (Chenopodiaceae) and Trigonella arcuata (Leguminosae). It should be particularly pointed out that ephemeral plants occupy a considerable proportion of the study area (Qian et al., 2013).

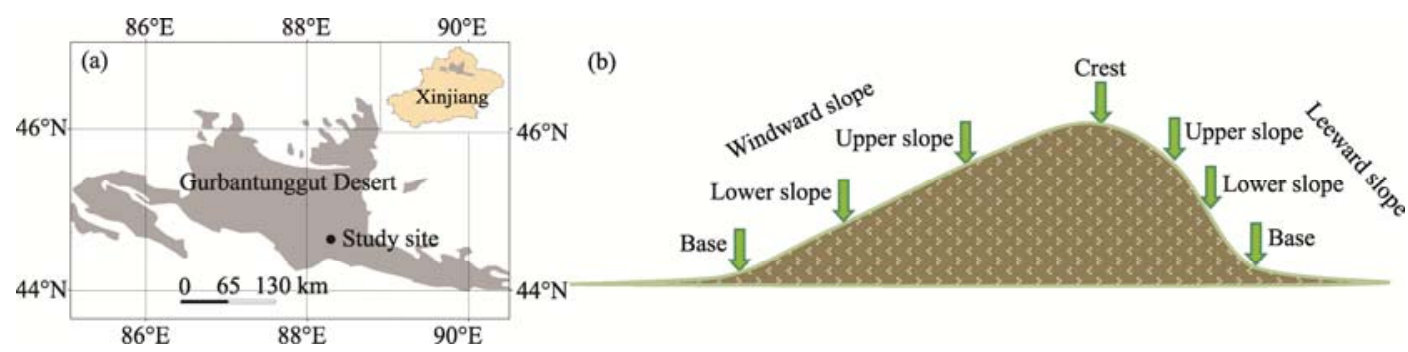

Fig. 1 Location of the study site (a) and sketch map of the longitudinal sand dune and the selected geographic positions (b)

\subsection{Sampling method and laboratory analysis}

In mid-February 2015, i.e., the period after seed dispersal and before seed germination, three representative longitudinal sand dunes were randomly selected in the southern region of the Gurbantunggut Desert. Furthermore, seven different geomorphic positions were selected in each longitudinal sand dune to examine the soil seed banks: base of the windward slope, base of the leeward slope, lower slope of the windward slope, lower slope of the leeward slope, upper slope of the windward slope, upper slope of the leeward slope, and crest (Fig. 1). For each selected longitudinal sand dune, five parallel transects (west-east direction) covered the seven geomorphic positions were established at $20-\mathrm{m}$ intervals. For each geomorphic position, five $1 \mathrm{~m} \times 1 \mathrm{~m}$ quadrates were designed. In each quadrat, three replicate soil cores $(10 \mathrm{~cm} \times 10 \mathrm{~cm} \times 10 \mathrm{~cm})$ were collected, and each soil core was separated into three soil samples with depths of $0-2,2-5$, and 5-10 cm, respectively. Then, soil samples from the same soil layer for each quadrat were well mixed. Finally, a total number of 315 soil samples were collected (i.e., three longitudinal sand dunes $\times$ five transects $\times$ seven geomorphic positions $\times$ three soil layers). In mid-April 2015 , all plant species aboveground were identified and recorded in each quadrat. Finally, the total number of plant species and species richness in each quadrat were determined.

In the laboratory, each soil sample was spread into a plastic germination tray $(25 \mathrm{~cm} \times 25 \mathrm{~cm} \times 7$ $\mathrm{cm}$ ) with 4-cm sterilized sand layer in the bottom. The depth of each soil sample was about $2 \mathrm{~cm}$. All the germination trays were placed in a greenhouse at the temperature of $15^{\circ} \mathrm{C}-25^{\circ} \mathrm{C}$ under natural light conditions. The soils were regularly watered with tap water (irrigation frequency of 3-6 days). After the seed germination, the seedlings were identified and counted every day. Seedlings were removed upon identification. Any unidentified seedlings were transferred to another tray to grow for later identification (Shang et al., 2016). Soil samples that present no seedlings in a two-week period after the onset of the germination experiments were carefully turned over and watered to improve the emergence of seedlings (Li et al., 2012). When there was no seedling emergence within another two-week period, soil samples were watered with the gibberellic acid $\left(\mathrm{GA}_{3}\right)$ solution for breaking the dormancy of seeds to obtain more seedlings (Caballero et al., 2008). The germination experiments lasted approximately 5 months for each soil sample. Finally, the total number of plant species and species richness of soil seed bank for each geomorphic position were determined according to the identification of seedlings.

\subsection{Data processing}

2.3.1 Plant species diversity indices

In this study, the Shannon-Wiener diversity index ( $H$; Eq. 1), Simpson's diversity index ( $\lambda$; Eq. 2), 
and Pielou's evenness index (E; Eq. 3) (Asadi et al., 2012) were used to evaluate the species diversity of soil seed banks and aboveground vegetation for each quadrat.

$$
\begin{gathered}
H^{\prime}=-\sum_{i=1}^{S} p_{i} \ln p_{i} . \\
\lambda=1-\sum_{i=1}^{S} p_{i}^{2} . \\
E=\frac{H^{\prime}}{\ln S} .
\end{gathered}
$$

Where, $p_{i}$ is the richness of the $i^{\text {th }}$ species for each quadrat and $S$ is the total number of plant species for each quadrat.

For soil seed banks, the relative frequency (\%) of each species was calculated by dividing the number of soil samples including the plant species by the total number of soil samples.

2.3.2 Similarity of plant species between soil seed banks and aboveground vegetation

The similarity of plant species between soil seed banks and aboveground vegetation for each quadrat was calculated using the Jaccard's similarity coefficient ( $I J_{S}$; Asadi et al., 2012).

$$
I J S=2 C /(2 C+A+B) \text {. }
$$

Where, $C$ is the number of plant species identified in both soil seed bank and aboveground vegetation for each quadrat; $A$ is the number of plant species identified in soil seed bank for each quadrat; and $B$ is the number of plant species identified in aboveground vegetation for each quadrat.

\subsection{Data analysis}

One-way analysis of variance (ANOVA) was used to examine the differences in species diversity indices and Jaccard's similarity coefficients between soil seed banks and aboveground vegetation among the seven geomorphic positions. Turkey's tests were used to evaluate the significance of the differences. Difference was considered significant at the $P<0.05$ level. All statistical analyses were performed with SPSS 9.0 software.

\section{Results}

\subsection{Floristic compositions of soil seed banks and aboveground vegetation}

Totally, 17 plant species belonging to 17 genera and 9 families were identified in soil seed banks (soil samples) based on seed germination experiments (Table 1). At the family level, Chenopodiaceae, Compositae, Gramineae, Cruciferae, and Leguminosae were larger families, accounting for $23.53 \%$ (4 species), $17.65 \%$ ( 3 species), $11.76 \%$ ( 2 species), $11.76 \%$ (2 species), and $11.76 \%$ ( 2 species) of all identified species, respectively. At the genus level, the proportions of all genera were equal, with one species for each. At the species level, the dominant species were Corispermum lehmannianum (Chenopodiaceae), Schismus arabicus (Gramineae), Alyssum linifolium (Cruciferae), and Erodium tibetanum (Cruciferae), with frequency $>35 \%$ for each. In terms of the life forms, ephemeral plants dominated the plant species composition, occupied 94.1\% (mean) of all identified species. Furthermore, perennial plants accounted for $5.9 \%$ (mean) of all identified species.

Totally, 35 plant species belonging to 34 genera and 17 families were identified in aboveground vegetation (Table 1). At the family level, Chenopodiaceae, Compositae, Gramineae, Cruciferae, Leguminosae, and Liliaceae were larger families, accounting for 20.00\% (7 species), 17.14\% (6 species), 8.57\% (3 species), 8.57\% (3 species), 8.57\% (3 species), and 8.57\% (3 species) of all identified species, respectively. At the genus level, the abundant genus was Astragalus (2 species). At the species level, the dominant species were E. tibetanum, Hyalea pulchella (Compositae), Salsola ruthenica (Chenopodiaceae), Carex physodes (Cyperaceae), and Eremurus inderiensis (Liliaceae). In terms of the life forms, ephemeral plants dominated the plant species composition, 


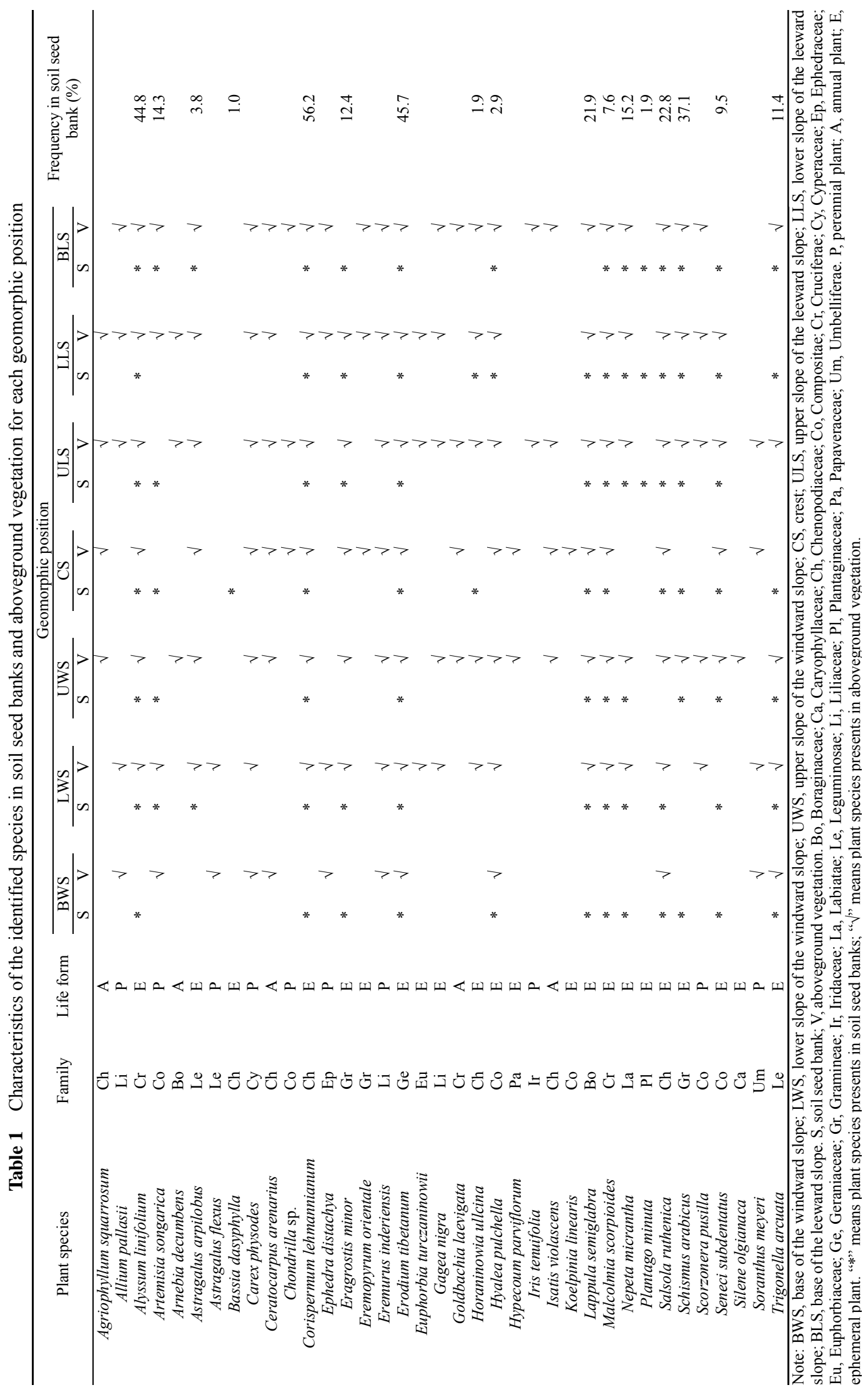


occupied $57.1 \%$ (mean) of all identified species. Furthermore, perennial plants and annual plants accounted for $28.6 \%$ (mean) and $14.3 \%$ (mean) of all identified species, respectively.

\subsection{Species characteristics of soil seed banks and aboveground vegetation}

\subsubsection{Species richness of soil seed banks and aboveground vegetation}

For soil seed banks, plant species richness was significantly different at the depth of $0-2 \mathrm{~cm}$ among the seven geomorphic positions $(F=2.91, P<0.05$; Table 2$)$. At the soil depth of $0-10 \mathrm{~cm}$, the highest species richness was presented in the lower slope of the leeward slope (3.80) and the lowest species richness was presented in the crest (1.80). As shown in Table 2, plant species richness in soil seed banks decreased gradually with increasing soil depth. For aboveground vegetation, species richness was significantly different among the seven geomorphic positions $(F=15.42, P<0.05$; Table 2$)$. The highest species richness was presented in the upper slope of the windward slope (5.18) and the lowest species richness was presented in the base of the windward slope (0.96).

Table 2 Total number of plant species and species richness in soil seed banks and aboveground vegetation for the seven geomorphic positions

\begin{tabular}{|c|c|c|c|c|c|c|c|c|}
\hline & \multirow{2}{*}{$\begin{array}{c}\text { Soil } \\
\text { depth } \\
(\mathrm{cm}) \\
\end{array}$} & \multicolumn{7}{|c|}{ Geomorphic position } \\
\hline & & BWS & LWS & UWS & $\mathrm{CS}$ & ULS & LLS & BLS \\
\hline \multicolumn{9}{|l|}{ Soil seed bank } \\
\hline \multirow{4}{*}{$\begin{array}{l}\text { Total number of } \\
\text { species }\end{array}$} & $0-2$ & 12 & 12 & 10 & 11 & 8 & 13 & 12 \\
\hline & $2-5$ & 4 & 6 & 3 & 3 & 7 & 9 & 9 \\
\hline & $5-10$ & 2 & 5 & 0 & 3 & 2 & 5 & 5 \\
\hline & $0-10$ & 12 & 13 & 10 & 12 & 11 & 14 & 14 \\
\hline \multirow{4}{*}{$\begin{array}{l}\text { Species richness } \\
\text { (individual/quadrat) }\end{array}$} & $0-2$ & $3.07 \pm 0.36^{\mathrm{a}}$ & $2.00 \pm 0.53^{\mathrm{ab}}$ & $2.20 \pm 0.45^{\mathrm{ab}}$ & $1.13 \pm 0.48^{\mathrm{b}}$ & $1.60 \pm 0.29^{\mathrm{ab}}$ & $2.87 \pm 0.39^{\mathrm{a}}$ & $2.47 \pm 0.24^{\mathrm{ab}}$ \\
\hline & $2-5$ & $0.33 \pm 0.13$ & $0.53 \pm 0.24$ & $0.40 \pm 0.21$ & $0.33 \pm 0.21$ & $1.07 \pm 0.21$ & $1.13 \pm 0.34$ & $0.67 \pm 0.29$ \\
\hline & $5-10$ & $0.20 \pm 0.11$ & $0.53 \pm 0.24$ & $0.00 \pm 0.00$ & $0.47 \pm 0.19$ & $0.20 \pm 0.14$ & $0.47 \pm 0.17$ & $0.33 \pm 0.16$ \\
\hline & $0-10$ & $3.33 \pm 0.39^{\mathrm{ab}}$ & $2.73 \pm 0.61^{\mathrm{ab}}$ & $2.40 \pm 0.47^{\mathrm{ab}}$ & $1.80 \pm 0.50^{\mathrm{b}}$ & $2.40 \pm 0.38^{\mathrm{ab}}$ & $3.80 \pm 0.40^{\mathrm{a}}$ & $3.00 \pm 0.32^{\mathrm{ab}}$ \\
\hline \multicolumn{9}{|l|}{ Aboveground vegetation } \\
\hline $\begin{array}{l}\text { Total number of } \\
\text { species }\end{array}$ & & 12 & 22 & 25 & 21 & 28 & 25 & 25 \\
\hline $\begin{array}{l}\text { Species richness } \\
\text { (individual/quadrat) }\end{array}$ & & $0.96 \pm 0.12^{\mathrm{c}}$ & $3.22 \pm 0.36^{\mathrm{b}}$ & $5.18 \pm 0.29^{\mathrm{a}}$ & $4.67 \pm 0.28^{\mathrm{ab}}$ & $4.49 \pm 0.39^{\mathrm{ab}}$ & $3.82 \pm 0.49^{\mathrm{ab}}$ & $3.18 \pm 0.42^{\mathrm{b}}$ \\
\hline
\end{tabular}

\subsubsection{Seed density of soil seed banks}

A total of 667 seedlings germinated from the soil samples (i.e., soil seed banks), with an average seed density of $362.1 \mathrm{seeds} / \mathrm{m}^{2}$. The values of seed density at the depth of $0-10 \mathrm{~cm}$ varied among the seven geomorphic positions, with the highest seed density of $583.3( \pm 90.6) \mathrm{seeds} / \mathrm{m}^{2}$ in the lower slope of the leeward slope and the lowest seed density of $247.8( \pm 109.1) \mathrm{seeds} / \mathrm{m}^{2}$ in the crest (Fig. 2a). At whole sand dune scale, there was no significant difference in seed density at the depth of $0-10 \mathrm{~cm}$ among those geomorphic positions $(F=1.947, P=0.081)$. However, for individual species, such as E. tibetanum and $S$. arabicus, significant differences in seed density existed at the depth of $0-10 \mathrm{~cm}$ among the geomorphic positions (see Figs. $2 \mathrm{~b}$ and c).

For individual species, the average seed density varied at three soil depths (Table 3). The total values of seed density for all plant species decreased with increasing soil depth, ranging from 103.3 to $363.3 \mathrm{seeds} / \mathrm{m}^{2}$ at the depth of $0-2 \mathrm{~cm}$, from 23.4 to $153.3 \mathrm{seeds} / \mathrm{m}^{2}$ at the depth of $2-5$ $\mathrm{cm}$, and from 0.0 to $81.1 \mathrm{seeds} / \mathrm{m}^{2}$ at the depth of 5-10 $\mathrm{cm}$ (Table 3). Seed density also followed a monotonic decreasing trend with increasing soil depth and also with the geomorphic positions (with exceptions of the lower slope of the windward slope and the crest; Fig. 3). Furthermore, there was a significant difference in seed density between the first $(0-2 \mathrm{~cm})$ and the second $(2-5$ $\mathrm{cm}$ ) soil layers and also among most of the geomorphic positions (with exceptions of the lower slope of the windward slope and the crest). It should be added that there was almost no significant difference in seed density between the second $(2-5 \mathrm{~cm})$ and the third $(5-10 \mathrm{~cm})$ soil layers. 


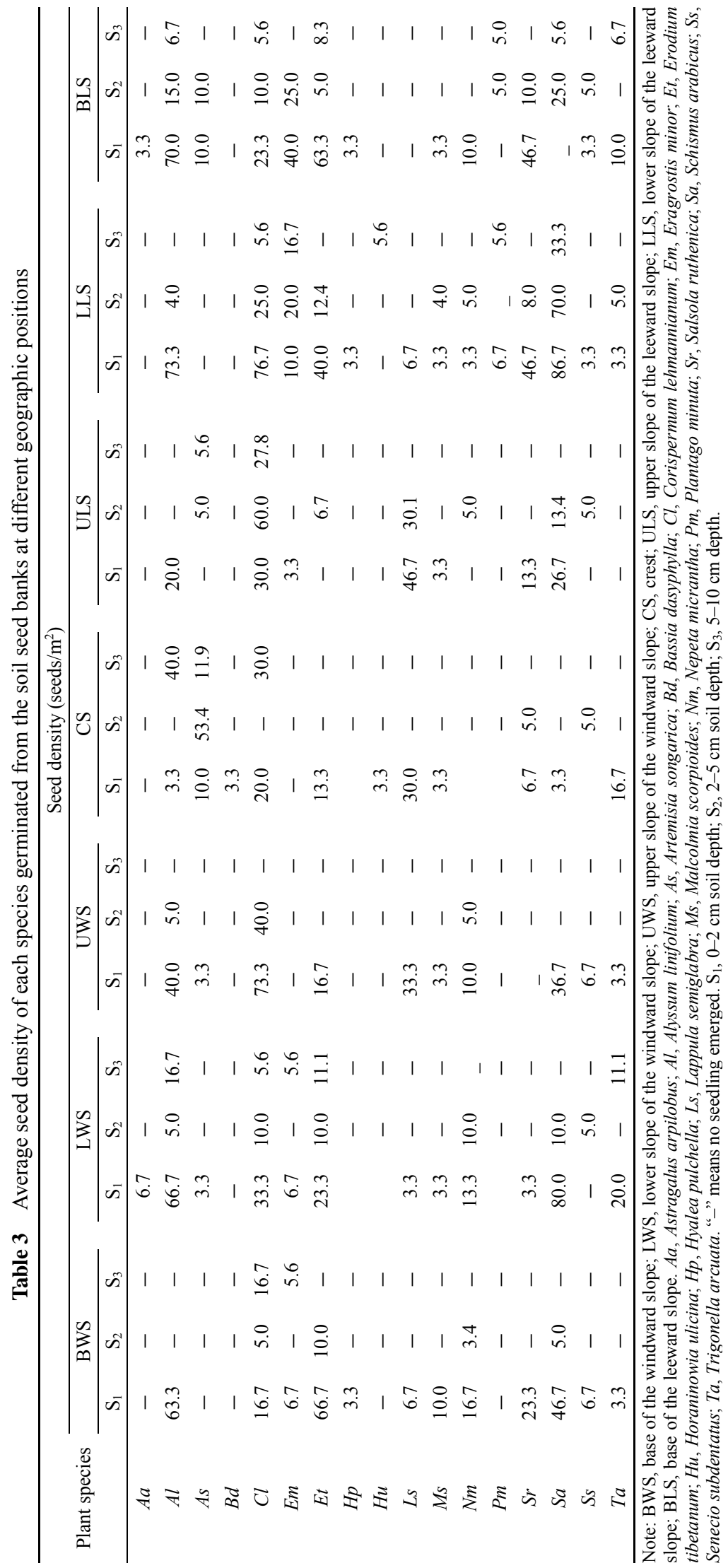




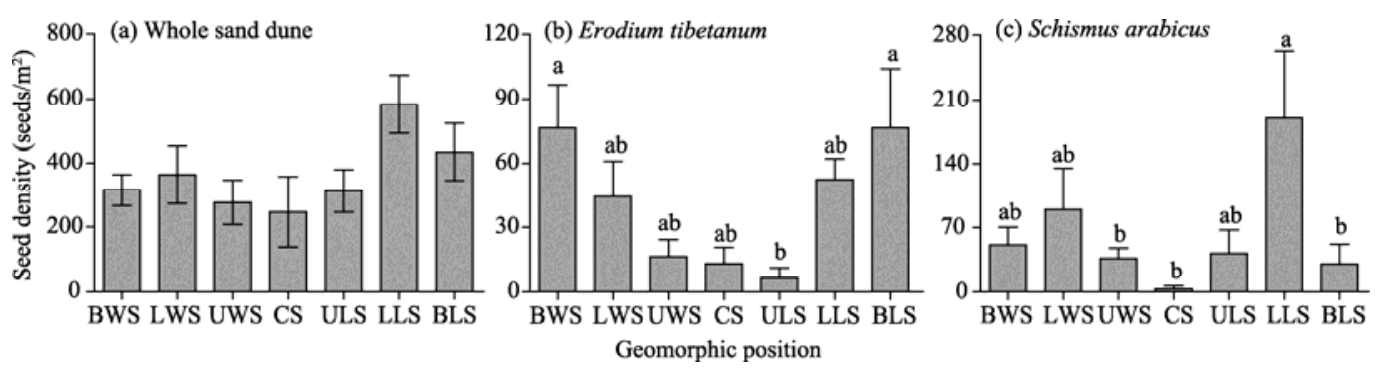

Fig. 2 Seed density of soil seed banks at the soil depth of $0-10 \mathrm{~cm}$ at whole sand dune scale (a) and individual species (b, c) across the seven geomorphic positions. BWS, base of the windward slope; LWS, lower slope of the windward slope; UWS, upper slope of the windward slope; CS, crest; ULS, upper slope of the leeward slope; LLS, lower slope of the leeward slope; BLS, base of the leeward slope. Different lowercase letters indicate significant differences $(P<0.05)$ among the geomorphic positions. Bars indicate standard errors.

(a) Whole sand dune

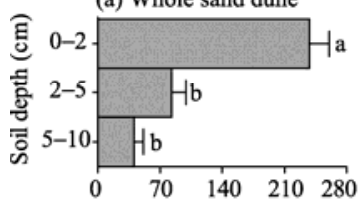

(e) $\mathrm{CS}$

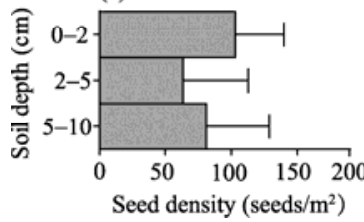

(b) BWS

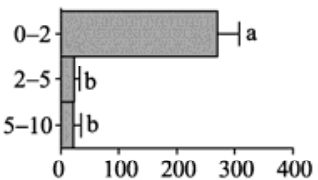

(f) ULS

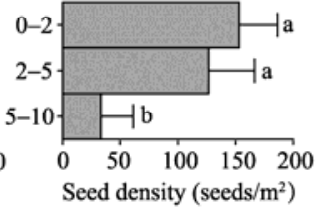

(c) LWS

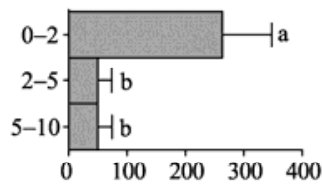

(g) LLS

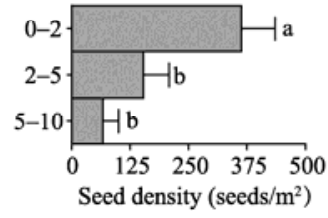

(d) UWS

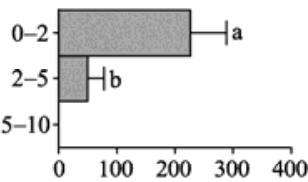

(h) BLS

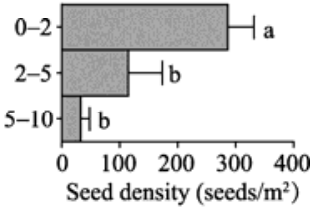

Fig. 3 Seed density of soil seed banks at three soil depths $(0-2,2-5$, and 5-10 cm) at whole sand dune scale (a) and at seven geomorphic positions $(\mathrm{b}-\mathrm{h})$. Different lowercase letters indicate significant differences $(P<0.05)$ among the geomorphic positions. Bars indicate standard errors.

\subsubsection{Species diversity indices of soil seed banks and aboveground vegetation}

Species diversity indices of soil seed banks and aboveground vegetation varied among the seven geomorphic positions (Table 4). There was no significant difference of Simpson's diversity index among the geomorphic positions for both soil seed banks and aboveground vegetation. However, significant differences of Shannon-Wiener diversity index and Pielou's evenness index existed among the geomorphic positions for soil seed banks and aboveground vegetation $(P<0.05)$.

Table 4 Species diversity indices of soil seed banks and aboveground vegetation for the seven geomorphic positions

\begin{tabular}{cccccccc}
\hline & \multicolumn{7}{c}{ Geomorphic position } \\
\cline { 2 - 8 } & BWS & LWS & UWS & CS & ULS & LLS & BLS \\
\hline Soil seed bank & & & & & \\
$H^{\prime}$ & $1.01 \pm 0.12^{\mathrm{a}}$ & $0.72 \pm 0.16^{\mathrm{ab}}$ & $0.68 \pm 0.16^{\mathrm{ab}}$ & $0.41 \pm 0.16^{\mathrm{b}}$ & $0.64 \pm 0.13^{\mathrm{ab}}$ & $1.01 \pm 0.12^{\mathrm{a}}$ & $0.90 \pm 0.10^{\mathrm{ab}}$ \\
$\lambda$ & $0.58 \pm 0.05$ & $0.60 \pm 0.08$ & $0.64 \pm 0.08$ & $0.43 \pm 0.11$ & $0.51 \pm 0.11$ & $0.54 \pm 0.06$ & $0.61 \pm 0.01$ \\
$E$ & $0.87 \pm 0.06^{\mathrm{a}}$ & $0.57 \pm 0.11^{\mathrm{ab}}$ & $0.53 \pm 0.12^{\mathrm{ab}}$ & $0.36 \pm 0.12^{\mathrm{b}}$ & $0.64 \pm 0.13^{\mathrm{ab}}$ & $0.76 \pm 0.07^{\mathrm{ab}}$ & $0.80 \pm 0.06^{\mathrm{a}}$ \\
& & & & & \\
Aboveground vegetation & $0.14 \pm 0.04^{\mathrm{d}}$ & $0.75 \pm 0.09^{\mathrm{c}}$ & $1.13 \pm 0.07^{\mathrm{a}}$ & $1.12 \pm 0.07^{\mathrm{a}}$ & $0.98 \pm 0.09^{\mathrm{ab}}$ & $0.82 \pm 0.11^{\mathrm{ab}}$ & $0.72 \pm 0.09^{\mathrm{c}}$ \\
$H^{\prime}$ & $0.40 \pm 0.07$ & $0.45 \pm 0.04$ & $0.56 \pm 0.03$ & $0.57 \pm 0.03$ & $0.52 \pm 0.04$ & $0.45 \pm 0.05$ & $0.38 \pm 0.05$ \\
$\lambda$ & $0.19 \pm 0.05^{\mathrm{d}}$ & $0.60 \pm 0.06^{\mathrm{ab}}$ & $0.70 \pm 0.03^{\mathrm{ab}}$ & $0.79 \pm 0.03^{\mathrm{a}}$ & $0.66 \pm 0.04^{\mathrm{ab}}$ & $0.57 \pm 0.06^{\mathrm{c}}$ & $0.57 \pm 0.06^{\mathrm{c}}$ \\
\hline & &
\end{tabular}

Note: $H^{\prime}$, Shannon-Wiener diversity index; $\lambda$, Simpson's diversity index; $E$, Pielou's evenness index. Values followed by different lowercase letters in the same row indicate significant differences $(P<0.05)$ among the geomorphic positions. Mean \pm SE.

For soil seed banks, both Shannon-Wiener diversity index and Pielou's evenness index were highest in the base of the windward slope and lowest in the crest. In contrast, the highest and lowest Pielou's evenness index values for aboveground vegetation appeared in the crest and the base of the windward slope, respectively. Furthermore, the highest Shannon-Wiener diversity 
index was found in the upper slope of the windward slope while the lowest was presented in the base of the windward slope.

\subsection{Relationship between soil seed bank and the aboveground vegetation}

As shown in Figure 4, the Jaccard's similarity coefficients of plant species between soil seed banks and aboveground vegetation at the seven geomorphic positions were low, ranging from 0.113 (upper slope of the leeward slope) to 0.196 (base of the leeward slope). There was no significant difference of the Jaccard's similarity coefficient between the geomorphic positions $(F=1.276, P>0.05)$.

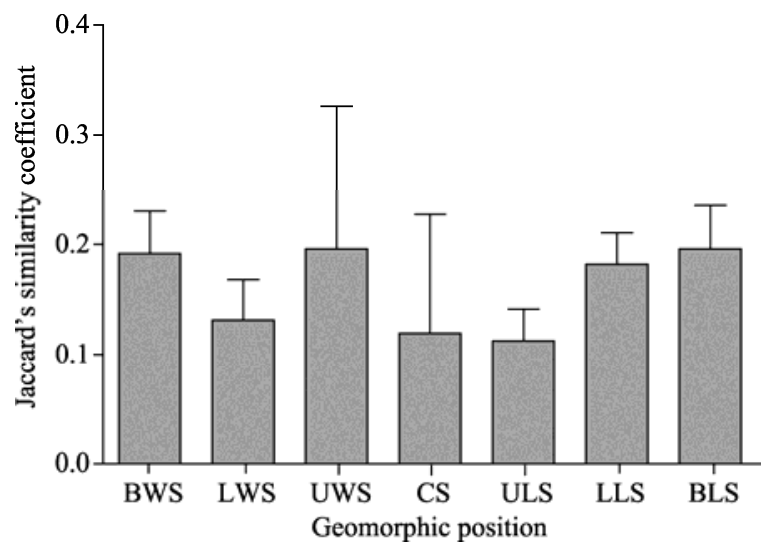

Fig. 4 Jaccard's similarity coefficients of plant species between soil seed banks and aboveground vegetation for the seven geomorphic positions. Bars indicate standard errors.

\section{Discussion}

\subsection{Species composition and diversity of soil seed banks}

In this study, 17 plant species were identified in the soil seed banks, being similar to the findings of other studies conducted in the Gurbantunggut Desert (Zhang et al., 2006; Wu et al., 2009) and the Taklimakan Desert (Li et al., 2007). However, being different from the soil seed banks in the Taklimakan Desert, ephemeral plants dominated the species composition of soil seed banks in the Gurbantunggut Desert. This phenomenon is the result of long-term natural selection and evolution (Li et al., 2015) and it is highly related to the hot climate in summer and cold climate in winter in the Gurbantunggut Desert (Wang, 1993). The result indicates that the ephemeral seed bank is the primary potential resources in the Gurbantunggut Desert and more attention should thus be paid to the ephemeral seed bank for vegetation restoration or reestablishment.

Among the seven geomorphic positions, the lower slope of the leeward slope showed the highest species richness. This may be due to the better hydrothermal conditions, less wind-erosion and little sand burial in this position (Qian et al., 2013). It is widely accepted that in desert ecosystems, soil water availability and soil erosion susceptibility are considered as the main factors determining seed dispersion and species richness of soil seed banks (e.g., Grigg et al., 2008; Kimball et al., 2010; Joubert et al., 2012; Auffret and Plue, 2014). At whole sand dune scale, geomorphic position, aspect, and micro-slope affect species richness and soil seed banks primarily through modulating soil water availability and soil erosion susceptibility (Parker, 1988; Caballero et al., 2003). Our result indicates that in the longitudinal sand dunes of the Gurbantunggut Desert, environment in the leeward slope is more suitable to the growth of plant species than in the crest and the windward slope, further confirming the proposition that soil water availability and soil erosion susceptibility are the main factors determining species richness of soil seed banks.

Significant differences in the Shannon-Wiener diversity index and Pielou's evenness index of soil seed banks existed among the seven geomorphic positions of the longitudinal sand dunes. It 
might be attributed to the following reasons: (i) the development and coverage of biological soil crusts, which affect the soil erosion susceptibility (Xing et al., 2016); (ii) topographic characteristics, which may influence various abiotic factors such as soil $\mathrm{pH}$, moisture, and nutrients (An et al., 2015); (iii) slope orientation, which is relevant to wind erosion and sand burial (Thompson et al., 2014); and (iv) aboveground vegetation distribution, which is directly related to all the above-mentioned reasons (García-Fayos et al., 2013). The aforementioned characteristics could jointly affect seed trap, seed germination, and seedling establishment of soil seed banks. It can be concluded that environmental factors play a significant role in the formation of soil seed banks.

\subsection{Seed density of soil seed banks}

In this study, the highest seed density of soil seed banks was found in the lower slope of the leeward slope and the lowest in the crest. Our results are rather different from the results reported by Yan et al. (2005) and their results showed that seed density of soil seed banks in the stabilized sand dunes in northeastern Inner Mongolia of China exhibited an increasing trend from the base to the crest. The crest of the selected stabilized sand dunes in the Gurbantunggut Desert was a sand-moving section enduring strong and frequent winds from April to October (Wang et al., 2003) and the seeds in the crest are easily transported to the leeward slope (Joubert et al., 2012; Miao et al., 2016). In addition, biological soil crusts, bare soil, and cracks existed more or less in rigid surfaces of sand dunes and between vegetation patches. And they were expected to negatively influence the soil seed banks (Caballero et al., 2008; Burmeier et al., 2010; Hernandez and Sandquist, 2011).

At each geomorphic position, seed density was higher in the shallow soil layer $(0-2 \mathrm{~cm})$ than in the deeper soil layers (i.e., 2-5 and 5-10 cm). Consequently, the shallow soil layer $(0-2 \mathrm{~cm})$ had the highest species richness and seed density. Our result is similar to the findings reported in other desert areas (Yu et al., 2003; Li et al., 2007). It should be added that seed density of soil seed banks showed a U-shaped pattern with increasing soil depth in the crest of sand dunes in this study. The U-shaped pattern may be related to wind erosion and sand burial (Ma and Liu, 2008). Specifically, soil erosion may result in seed aggregation in the shallow soil layer whereas sand burial may result in seed agglomeration in the deep soil layer. It should be particularly noted that the observed seed agglomeration in the deep soil layer may be resulted from hygroscopic movement of seed appendages (García-Fayos et al., 2013).

\subsection{Relationship between soil seed banks and aboveground vegetation and its implication}

As a valuable basis, the relationship between soil seed banks and aboveground vegetation has been widely used in vegetation restoration or reestablishment in recent years. However, no consensus has been reached regarding the similarities of plant species between soil seed banks and aboveground vegetation, and even some of the results were contradictory (e.g., Thompson and Baster, 1992; Li et al., 2012). For example, Thompson and Baster (1992) found a high similarity between soil seed banks and aboveground vegetation, while Li et al. (2012) observed a low similarity between them. In this study, all the similarity coefficients of plant species between soil seed banks and aboveground vegetation at the examined seven geomorphic positions were low, especially in the lower slope of the windward slope, the crest, and the upper slope of the leeward slope. The low similarity coefficients may be attributed to the following reasons. First, the growth and development of perennial species mainly depend on their ability to colonize by means of root-derived, stem-derived and other organs-derived propagations, rather than by seed reproduction (Zhang and Zhang, 2007; Wang et al., 2010; Zhang and Wu, 2014). Second, the seed predators may reduce the seed density, thus disassociating the vegetation seeds with soil seeds (Ruano et al., 2015; Sprengelmeyer and Rebertus, 2015). Third, biological soil crusts may also have a negative impact on soil seed banks by preventing the contacts of seeds with soils (Prasse and Bornkamm, 2000) or inhibiting the seed from germination (Deines et al., 2007; Liu et al., 
2014; Zhang and Belnap, 2015).

\section{Conclusions}

Our results indicated that although there were no significant differences in seed density of soil seed banks among the examined seven geomorphic positions, the geomorphic positions significantly contributed to the differences in species richness, diversity, and distribution of soil seed banks. Therefore, understanding the characteristics of soil seed banks at different geomorphic positions of sand dunes is essential to vegetation restoration or reestablishment. Our results show that seed density of soil seed banks was highest in the shallow soil layer (i.e., 0-2 $\mathrm{cm}$ ), suggesting that desert vegetation restoration or reestablishment could be implemented by the methods of soil seed bank in-situ germination. The low similarity of plant species between soil seed banks and aboveground vegetation over various geomorphic positions of sand dunes suggests that the vegetation restoration or reestablishment processes can be promoted through adding seeds to the surface layers.

\section{Acknowledgements}

This study was financially supported by the National Natural Science Foundation of China (41571256), the National Natural Science Foundation of China-Xinjiang Mutual Funds (U1503101) and the Natural Science Foundation of Xinjiang, China (2015211C292). We thank all the members of the Key Laboratory of Biogeography and Bioresources in Arid Land, Xinjiang Institute of Ecology and Geography, Chinese Academy of Sciences for their assistance in the field.

\section{References}

An P, Li X J, Zheng Y R, et al. 2015. Distribution of plant species and species-soil relationship in the east central Gurbantunggut Desert, China. Journal of Geographical Sciences, 25(1): 101-112.

Asadi H, Hosseini S M, Esmailzadeh O, et al. 2012. Persistent soil seed banks in old-growth Hyrcanian Box tree (Buxus hyrcana) stands in northern Iran. Ecological Research, 27(1): 23-33.

Auffret A G, Plue J. 2014. Scale-dependent diversity effects of seed dispersal by a wild herbivore in fragmented grasslands. Oecologia, 175(1): 305-313.

Bekker R M, Bakker J P, Grandin U, et al. 1998. Seed size, shape and vertical distribution in the soil: indicators of seed longevity. Functional Ecology, 12(5): 834-842.

Burmeier S, Eckstein R L, Otte A, et al. 2010. Desiccation cracks act as natural seed traps in flood-meadow systems. Plant and Soil, 333(1): 351-364.

Caballero I, Olano J M, Loidi J, et al. 2003. Seed bank structure along a semi-arid gypsum gradient in Central Spain. Journal of Arid Environments, 55(2): 287-299.

Caballero I, Olano J M, Escudero A, et al. 2008. Seed bank spatial structure in semi-arid environments: beyond the patch-bare area dichotomy. Plant Ecology, 195(2): 215-223.

Decocq G, Valentin B, Toussaint B, et al. 2004. Soil seed bank composition and diversity in a managed temperate deciduous forest. Biodiversity and Conservation, 13(13): 2485-2509.

Deines L, Rosentreter R, Eldridge D J, et al. 2007. Germination and seedling establishment of two annual grasses on lichen-dominated biological soil crusts. Plant and Soil, 295(1-2): 23-35.

Devictor V, Moret J, Machon N. 2007. Impact of ploughing on soil seed bank dynamics in temporary pools. Plant Ecology, 192(1): 45-53.

Espinar J L, Thompson K, García L V. 2005. Timing of seed dispersal generates a bimodal seed bank depth distribution. American Journal of Botany, 92(10): 1759-1763.

García-Fayos P, Engelbrecht M, Bochet E. 2013. Post-dispersal seed anchorage to soil in semiarid plant communities, a test of the hypothesis of Ellner and Shmida. Plant Ecology, 214(7): 941-952.

Grigg A M, Veneklaas E J, Lambers H. 2008. Water relations and mineral nutrition of closely related woody plant species on desert dunes and interdunes. Australian Journal of Botany, 56(1): 27-43.

Hernandez R R, Sandquist D R. 2011. Disturbance of biological soil crust increases emergence of exotic vascular plants in California sage scrub. Plant Ecology, 212(10): 1709-1721. 
Huang Z Y, Gutterman Y. 1998. Artemisia monosperma achene germination in sand: effects of sand depth, sand/water content, cyanobacterial sand crust and temperature. Journal of Arid Environments, 38(1): 27-43.

Hyatt L A, Casper B B. 2000. Seed bank formation during early secondary succession in a temperate deciduous forest. Journal of Ecology, 88(3): 516-527.

Joubert E C, Harms T M, Muller A, et al. 2012. A CFD study of wind patterns over a desert dune and the effect on seed dispersion. Environmental Fluid Mechanics, 12(1): 23-44.

Kimball S, Angert A, Huxman T E, et al. 2010. Contemporary climate change in the Sonoran Desert favors cold-adapted species. Global Change Biology, 16(5): 1555-1565.

Lawton R O, Putz F E. 1988. Natural disturbance and gap-phase regeneration in a wind-exposed tropical cloud forest. Ecology, 69(3): 764-777.

Leicht-Young S A, Pavlovic N B, Grundel R, et al. 2009. A comparison of seed banks across a sand dune successional gradient at Lake Michigan dunes (Indiana, USA). Plant Ecology, 202(2): 299-308.

Li C M, Long L, Xu C L, et al. 2015. Characteristics of soil seed banks of alpine meadow under different degradation degrees in eastern Qilian Mountains. Acta Agrestia Sinica, 23(5): 957-962. (in Chinese)

Li N, Feng G, Tian C Y. 2007. Characteristics and dynamics of the soil seed bank at the north edge of Taklimakan Desert. Science in China Series D: Earth Sciences, 50(Suppl. 1): 122-127.

Li Y Y, Dong S K, Wen L, et al. 2012. Soil seed banks in degraded and revegetated grasslands in the alpine region of the Qinghai-Tibetan Plateau. Ecological Engineering, 49: 77-83.

Lindner A. 2009. A rapid assessment approach on soil seed banks of Atlantic forest sites with different disturbance history in Rio de Janeiro, Brazil. Ecological Engineering, 35(5): 829-835.

Liu H L, Shi X, Wang J C, et al. 2011. Effects of sand burial, soil water content and distribution pattern of seeds in sand on seed germination and seedling survival of Eremosparton songoricum (Fabaceae), a rare species inhabiting the moving sand dunes of the Gurbantunggut Desert of China. Plant and Soil, 345(1-2): 69-87.

Liu Q Y, Jiang M, Lü X G, et al. 2014. A review of similarity between soil seed bank and aboveground vegetation in wetlands. Acta Ecologica Sinica, 34(24): 7465-7474. (in Chinese)

Luo N, Liu Z C, Yu H, et al. 2016. Regional differences in plant diversity in the southern Gurbantonggut desert. Acta Ecologica Sinica, 36(12): 3572-3581. (in Chinese)

Ma J L, Liu Z M. 2008. Spatiotemporal pattern of seed bank in the annual psammophyte Agriophyllum squarrosum Moq. (Chenopodiaceae) on the active sand dunes of northeastern Inner Mongolia, China. Plant and Soil, 311(1): $97-107$.

Miao C P, Li X H, Jia M Y, et al. 2016. Spatial structure and species composition of soil seed banks in moving sand dune systems of northeast China. Journal of Forestry Research, 27(1): 75-80.

Parker K C. 1988. Environmental relationships and vegetation associates of Columnar cacti in the northern Sonoran Desert. Vegetatio, 78(3): 125-140.

Prasse R, Bornkamm R. 2000. Effect of microbiotic soil surface crusts on emergence of vascular plants. Plant Ecology, 150(1-2): 65-75.

Qian Y B, Wu Z N, Wang Z C, et al. 2013. Relationship of spatial heterogeneity for vegetation and Aeolian sand soil properties on longitudinal dunes in Gurbantunggut Desert, China. Environmental Earth Sciences, 69(6): 2027-2036.

Ruano I, del Peso C, Bravo F. 2015. Post-dispersal predation of Pinus pinaster Aiton seeds: key factors and effects on belowground seed bank. European Journal of Forest Research, 134(2): 309-318.

Shang Z H, Yang S H, Wang Y L, et al. 2016. Soil seed bank and its relation with above-ground vegetation along the degraded gradients of alpine meadow. Ecological Engineering, 90: 268-277.

Song Y Y, Zhou C B, Zhang W H. 2011. Vegetation coverage, species richness, and dune stability in the southern part of Gurbantünggüt Desert. Ecological Research, 26(1): 79-86.

Sprengelmeyer E E, Rebertus A J. 2015. Seed bank dynamics in relation to disturbance and landscape for an ant-dispersed species. Plant Ecology, 216(3): 371-381.

Thompson K, Baster K. 1992. Establishment from seed of selected Umbelliferae in unmanaged grassland. Functional Ecology, 6(3): 346-352.

Thompson S E, Assouline S, Chen L, et al. 2014. Secondary dispersal driven by overland flow in drylands: review and mechanistic model development. Movement Ecology, 2: 7.

Wang N, Jiao J Y, Jia Y F, et al. 2010. Germinable soil seed banks and the restoration potential of abandoned cropland on the Chinese Hilly-Gullied Loess plateau. Environmental Management, 46(3): 367-377.

Wang X Q, Jiang J, Lei J Q, et al. 2003. The distribution of ephemeral vegetation on the longitudinal dune surface and its stabilization significance in the Gurbantunggut Desert. Acta Geographica Sinica, 58(4): 598-605. (in Chinese) 
Wang X Q, Zhang Y M, Jiang J, et al. 2009. Effects of spring-summer grazing on longitudinal dune surface in southern Gurbantunggut Desert. Journal of Geographical Sciences, 19(3): 299-308.

Wang Y. 1993. Phenological observation of the early spring ephemeral and ephemeroid plant in Xinjiang. Arid Zone Research, 10(3): 34-39. (in Chinese)

Wu T, Wang X Q, Gai S G, et al. 2009. Effect of grazing in spring-summer on soil seed bank and vegetation in southern part of Gurbantunggut Desert. Journal of Desert Research, 29(3): 499-507. (in Chinese)

Xing X M, Ma X D, Zhang Y M. 2016. Effects of biological soil crusts on soil seed bank diversity and distribution characteristics in Gurbantunggut Desert. Chinese Journal of Ecology, 35(3): 612-620. (in Chinese)

Yan Q L, Liu Z M, Zhu J J, et al. 2005. Structure, pattern and mechanisms of formation of seed banks in sand dune systems in northeastern Inner Mongolia, China. Plant and Soil, 277(1-2): 175-184.

Yan Q L, Liu Z M, Zhu J J. 2009. Temporal variation of soil seed banks in two different dune systems in northeastern Inner Mongolia, China. Environmental Geology, 58(3): 615-624.

Yu S L, Sternberg M, Jiang G M, et al. 2003. Heterogeneity in soil seed banks in a Mediterranean coastal sand dune. Acta Botanica Sinica, 45(5): 536-543.

Zhang J Y, Wu Y X. 2014. Changes in diversity and importance of clonal plants during sand dune succession in northeastern China. Ecological Research, 29(3): 393-399.

Zhang R, Liu T. 2012. Plant species diversity and community classification in the southern Gurbantunggut Desert. Acta Ecologica Sinica, 32(19): 6056-6066. (in Chinese)

Zhang T, Tian C Y, Sun Y, et al. 2006. Soil seed banks of ephemerals in the Gurbantunggut Desert area. Arid Land Geography, 29(5): 675-681. (in Chinese)

Zhang Y F, Zhang D Y. 2007. Asexual and sexual reproductive strategies in clonal plants. Frontiers of Biology in China, 2(3): 256-262.

Zhang Y M, Belnap J. 2015. Growth responses of five desert plants as influenced by biological soil crusts from a temperate desert, China. Ecological Research, 30(6): 1037-1045. 